\title{
A Semana da Consciência Negra em uma Escola Periférica: Narrativas de um Trabalho Coletivo
}

\author{
FERRARESE, Elaine da Silveira Ribeiro ${ }^{1}$ \\ OLIVEIRA, Tamires da Silva²
}

\section{RESUMO}

O objetivo do trabalho é inscrever os enfrentamentos para implementação de um projeto interdisciplinar em escola pública periférica, sobre a cultura afrobrasileira. Justifica-se a partir de evidências cotidianas e estatísticas onde os sujeitos negros são "invisibilizados" nas narrativas que compõem a identidade nacional brasileira. Pelas narrativas das professoras ${ }^{3}$ envolvidas no projeto, buscou-se problematizar, contextualizar e refletir a partir de bibliografia majoritariamente negra, as crises e dramas do cotidiano escolar específicos ao recorte racial. Considera-se que professoras e professores necessitam fazer voz para que a prática de enaltecer a pluralidade de existências e a luta do povo negro no Brasil ocorra não apenas em datas específicas, mas ao longo de todo $o$ ano letivo.

Consciência negra. Racismo. Escola. Narrativas. Projeto interdisciplinar.

\section{Black awareness week in a peripheral elementary school: narratives of a collective work}

\section{ABSTRACT}

The work objective is to register the confrontations for the implementation of an interdisciplinary project in a peripheral public school, about Afro-Brazilian culture. It is justified based on daily evidence and statistics where black people are "invisible" in the narratives that make up the Brazilian national identity. Through the narratives of the teachers involved in the project, we sought to problematize, contextualize, and reflect from a mostly black bibliography, such as crises and dramas of the school routine specifics to the racial profile. It is considered that qualified teachers need to make a voice so that the practice of extolling the

\footnotetext{
${ }^{1}$ Doutoranda pela UNIMEP na linha de pesquisa Trabalho Docente, Formação de Professores e Políticas Educacionais. Email: elaineferrarese@hotmail.com. Lattes: http://lattes.cnpq.br/2252266198050608. Orcid: https://orcid.org/0000-0003-0694-6617.

${ }^{2}$ Pedagoga e Graduada nos módulos Licenciatura e Bacharelado pela Faculdade de Ciências Sociais, da Pontifícia Universidade Católica de Campinas. Email: tams.oliveira94@gmail.com. Lattes: http://lattes.cnpq.br/1418792312745268. Orcid: https://orcid.org/0000-0001-8923-461X.

${ }^{3}$ Durante todo o ensaio adotamos professora (feminino) como marcação política de gênero da classe. Na escola a que se refere o trabalho, todo o corpo docente era feminino, com exceção de 2 (dois) professores de educação física.
} 
plurality of existences and the struggle of the black people in Brazil occurs not only on specific dates, but throughout the school year.

Black awareness. Racism. School. Narratives. Interdisciplinary project.

\section{La Semana de la conciencia negra en una escuela periférica: narrativas de un trabajo colectivo}

\section{RESUMEN}

El objetivo del trabajo es registrar los enfrentamientos para la implementación de un proyecto interdisciplinario en una escuela pública periférica, sobre la cultura afrobrasileña. Se justifica con base en evidencias y estadísticas diarias donde los sujetos negros son "invisibilizados" en las narrativas que conforman la identidad nacional brasileña. A través de las narrativas de las docentes involucradas en el proyecto, se buscó problematizar, contextualizar y reflexionar desde una bibliografía mayoritariamente negra, las crisis y dramas de la rutina escolar propios del contorno racial. Se considera que las profesoras y los profesores necesitan hacer una voz para que la práctica de ensalzar la pluralidad de existencias y la lucha del pueblo negro en Brasil ocurra no solo en fechas específicas, sino durante todo el año escolar.

conciencia negra. Racismo. Escuela. Narrativas. proyecto interdisciplinario.

\section{Settimana della consapevolezza nera in una scuola periferica: racconti di un lavoro collettivo}

\section{SOMMARIO}

L'obiettivo del lavoro è registrare i confronti per l'attuazione di un progetto interdisciplinare in una scuola pubblica periferica, sulla cultura afro-brasiliana. È giustificato sulla base di prove e statistiche quotidiane in cui i soggetti neri sono "invisibili" nelle narrazioni che compongono l'identità nazionale brasiliana. Attraverso le narrazioni dei docenti coinvolti nel progetto si è cercato di problematizzare, contestualizzare e riflettere da una bibliografia prevalentemente nera, le crisi e i drammi della routine scolastica tipica del profilo razziale. Si ritiene che gli insegnanti e le insegnanti debbano farsi una voce in modo che la pratica di esaltare la pluralità delle esistenze e la lotta dei neri in Brasile avvenga non solo in date specifiche, ma durante l'intero anno scolastico.

Coscienza nera. Razzismo. Scuola. Narrazioni. progetto interdisciplinare.

\section{INTRODUÇÃO}

Viver o cotidiano escolar é viver no plural. Os cotidianos. Muitos lugares num único espaço. Lidamos aqui com realidades. São múltiplas, diversas, coloridas. São vivas. O que pretende-se neste trabalho - para além da

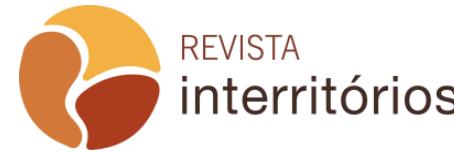


organização verbal de todo o processo de implementação de um projeto voltado para a temática do Dia Nacional da Consciência Negra que ocorre em 20 de Novembro - é substancialmente evidenciar a rede de relações que se estruturam no ambiente escolar e que, em muitos momentos, pode dificultar e adormecer as potencialidades transgressoras do ser diverso, curioso e inventivo.

Trazemos para esse texto as experiências de um trabalho coletivo que ocorreu no ano de 2019 em uma escola pública do Ensino Fundamental I. Para Rubtsov (1996, p. 136) os principais elementos de um trabalho coletivo são a repartição das ações e operações iniciais da atividade, a troca de modos de ação, o planejamento de ações individuais com objetivo a um resultado comum e a reflexão que permite superar as ações individuais transformando-as em trabalho coletivo.

Assim, nossa intenção inicial ao pensar em um projeto interdisciplinar para a semana da consciência negra foi no sentido de uma atividade coletiva e alcançar com ela a necessidade de um grupo. Que todos - alunos e alunas, funcionários e professoras - pudessem se apropriar de bens culturais produzidos coletivamente. Ao abraçar o trabalho coletivamente, assumimos juntas os riscos e demandas de afazeres extras que as atividades nos trariam. Quando apresentamos a proposta para as gestoras fomos na convicção de que o projeto, com todas as suas demandas, seria de responsabilidade não de uma única pessoa, mas de um coletivo. É a história desse coletivo que compartilhamos nesse texto.

Para melhor composição da memória voltamos aos nossos cadernos de planejamento, fotos, e-mails e conversas trocadas entre nós e com todos aqueles que fizemos contato em busca de apoio em todo o percurso do projeto. A partir do nosso retorno a esses materiais acertamos que cada uma faria suas narrativas do significado daquela experiência, ou seja, as narrativas foram construídas no mês de agosto de 2020.

Reconhecemos que trabalhar com narrativas (auto)biográficas é um processo complexo, é olhar para dentro de si e encontrar palavras que definam a experiência vivida e os sentidos atribuídos a elas. São narrativas que envolvem múltiplas vozes, que foram se entrelaçando ao longo do processo de rememorar o vivido.

O que dá forma ao vivido e à experiência dos homens são as narrativas que eles fazem de si. A narração não é apenas o instrumento de formação, a linguagem na qual esta se expressaria: a narração é o lugar no qual o indivíduo toma forma, no qual ele elabora experimenta a história de sua vida. (DELORY-MOMBERGER, 2008, p. 56)

Entendemos, também, que a narrativa contribui para o leitor e para 0 autor, pois o ato da escrita narrativa não se relaciona apenas às lembranças dos

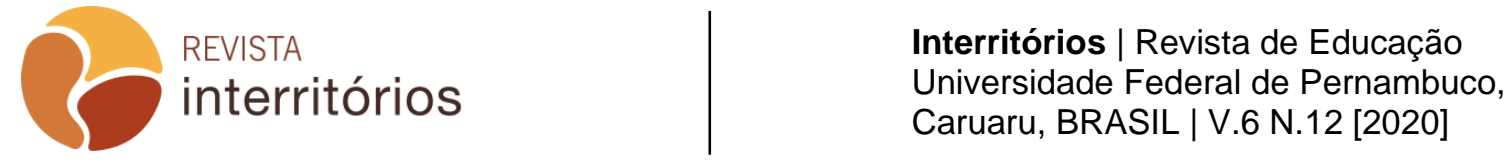


fatos passados, mas a todo um processo reflexivo das experiências a serem narradas. (MARQUESIN, NACARATO, 2018, p. 94). Ela é um instrumento potente para a percepção da formação continuada que ocorre na escola, assim é possível ver na narrativa a professora como produtora de novos conhecimentos, bem como um sujeito corresponsável por sua formação e de seus pares. (FERREIRA, ARAGÃO, PREZOTTO, 2015, p. 21). Nesse sentido,

[...] narrar, neste contexto, é modo de exprimir o que é vivido com intensidade, deixando transparecer os conflitos, ambivalências e as percepções sensíveis que se desencadeiam. São registros que convocam a professora a se incluir na escrita, marcando posição diante do vivido. (idem, p. 22).

Esse é, portanto, um ensaio que tem como tema refletir sobre as narrativas das professoras envolvidas em um trabalho coletivo sobre a Semana da Consciência Negra, com o objetivo de pontuar os desafios para implementação de um projeto sobre a cultura afro-brasileira. Nesse sentimos, debruçamo-nos nas análises das narrativas em interlocução com um referencial teórico pautado nas contribuições de bell hooks (2017), Carneiro (1995, 2011), Almeida (2020), Kilomba (2019) e Oliveira (2009). Metodologicamente, o estudo narrativo de cunho (auto)biográfico se mostra acertado, pois pretendemos evidenciar os saberes provenientes da prática profissional e as reflexões construídas coletivamente no cotidiano da escola. (PRADO et al. 2019).

Assim, organizamos o texto em seis partes incluindo essa introdução. $\mathrm{Na}$ segunda parte apresentamos como se deu nosso encontro e as características do local onde ocorreu o projeto. Na terceira, refletimos sobre os enfrentamentos vivenciados para a implementação do projeto. Na quarta parte, trouxemos sobre as experiências partilhadas com profissionais que vieram de outros espaços. $\mathrm{Na}$ quinta parte refletimos sobre nossas impressões sobre a participação dos alunos e alunas. Por fim, encerramos com as percepções sobre a realização do projeto como um todo, tanto para a prática pedagógica, quanto para os sujeitos envolvidos no processo: professoras, alunos e alunas, e gestoras da instituição escolar.

\section{Pedagogia do encontro: dividindo ideias, multiplicando sonhos}

A escola é um espaço de encontros. O encontro com o outro. Com aquele que é diferente da gente. E foi em uma escola que nos encontramos. Somos duas professoras do Ensino Fundamental I (Elaine e Tamires) e uma professora de Educação Física (Marina ${ }^{4}$ ). Chegamos na escola em 2017, 2019 e 2018

\footnotetext{
${ }^{4}$ Agradecemos à professora Marina pela parceria durante o projeto e por suas narrativas cedidas para a elaboração do ensaio, mesmo estando impossibilitada de participar da escrita.

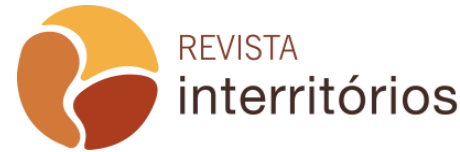


respectivamente. Éramos diferentes em muitos aspectos, mas muito parecidas no que diz respeito ao nosso olhar para a escola. Acreditamos efetivamente na integração das diferenças para estabelecer reciprocidade nas relações escolares, isto é, a escola enquanto espaço de compartilhamento de ideias e modos diferentes de ser no mundo, necessita assumir e problematizar a preterição de algumas existências em relação a outras. (HOOKS, 2017, p. 143).

Nem sempre somos unidos apenas por nossas semelhanças, muitas vezes o que nos une é justamente as diferenças e a maneira como o outro a acolhe. $O$ desenvolvimento do projeto que vamos apresentar e a escrita deste texto se deu por uma professora negra e duas professoras brancas. Fato importante de demarcar, pois foram muitas as trocas entre nós referente a questões raciais que nos atravessam e atravessam o contexto escolar em que estávamos inseridas. Como afirma Hooks (2017, p. 147), a possibilidade de imprimir a subjetividade umas nas outras e compartilhar de uma consciência, a partir de diálogos críticos e que, ao mesmo tempo externalizam a intensidade afetiva, potencializaram o engajamento do projeto nas dinâmicas de relações inter-raciais que compõem o cotidiano da instituição de ensino na qual atuávamos.

A escola do nosso encontro, vivências e trocas de experiências localizase em região periférica de uma cidade de médio porte no estado de São Paulo. Os bairros que rodeiam a escola são compostos, em sua maioria, por famílias de migrantes, vindos principalmente dos estados de Minas Gerais e Bahia. Ainda próximo da escola há duas favelas ${ }^{5}$ e 0 tráfico de drogas é uma atividade recorrente na região e realizada independente do horário e/ou local.

A instituição de ensino que oferece os anos iniciais do ensino fundamental (1 ano até $05^{\circ}$ ano) abriga - em sua estrutura simples e sem recursos arquitetônicos e/ou tecnológicos significativos - aproximadamente 650 alunos e alunas, com a maioria de estudantes não brancos e famílias de diferentes composições. Por outro lado, ao pensar o quadro funcional da instituição de ensino, a composição do corpo docente da escola é majoritariamente branca, contrapondo-se ao quadro de serviços gerais, que assim como a composição de alunos e alunas, é majoritariamente não branca.

\footnotetext{
${ }^{5} \mathrm{~A}$ escolha do termo favela para o presente trabalho é intencional e política. Sabe-se que quaisquer realidades são passíveis de problematizações e de explicações, sendo as condições de moradia uma delas. Com os diferentes termos usados para determinar as especificidades habitacionais (bairro, conjunto habitacional, comunidades ou favela) entendemos que historicamente o conceito de favela exprime de maneira direta e cirúrgica todas as contradições da sociedade contemporânea e tecnologicamente avançada. Não queremos, aqui, maquiar ou atenuar as limitações e as fragilidades socioeconômicas da comunidade escolar na qual atuamos. É preciso "colocar os pingos nos Is". Como compreender, por exemplo, a estrutura social, cultural, política e econômica que permite a coexistência de um centro urbano da magnitude da cidade de São Paulo com uma das maiores favelas do Brasil, a Favela de Paraisópolis? Tal discussão caberia para outro recorte que não é o nosso, mas tomamos aqui a escolha por evidenciar as contradições que perpassam o cotidiano escolar.
}

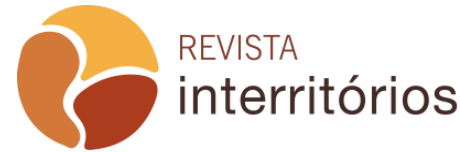


Era o início do mês de outubro, o último bimestre do ano. Bimestre cansativo para as professoras, alunos e alunas, e gestoras. Apesar do cansaço, sabemos que há muito a ser feito e desenvolvido nessa reta final. Alguns temas específicos que devem ser incluídos na agenda como, a semana do dia das crianças, o dia da Consciência Negra, ensaios para a Cantata de Natal. Dos três temas o menos trabalhado na escola era o dia da Consciência Negra, que era marcado apenas com algumas histórias e pinturas de desenhos. Cada professora tinha a liberdade de trabalhar o tema como achasse melhor, infelizmente muitas faziam a opção por não trabalhar o tema.

Essa era uma inquietação que me atravessava. Como professora negra, não queria mais que o tema ficasse na superficialidade, recordo que falei primeiro com a Marina, disse que estava cansada de ficar levando atividades de lista e pinturas sobre a Semana da Consciência Negra. A sensação era que estava apenas tapando um buraco. Queria que organizássemos algo relevante. Um projeto que envolvesse a escola toda. Me lembro que a Marina, movida pelo afeto prontamente aceitou. Levei a ideia em seguida para a Tamires, que também aceitou com alegria. Assim, faltando pouco mais de um mês para 20 de novembro, levamos à nossa coordenação o desejo de elaborar um projeto específico para a Semana da Consciência Negra que envolvesse toda a escola. A ideia foi aceita pelas gestoras, sem muitos questionamentos e começamos a trabalhar. [Elaine]

E foi assim, em nossas conversas pelos corredores da escola, da inquietação de uma professora e da disposição de outras que surgiu o projeto. Após a autorização das gestoras, sentamo-nos para a escrita, que foi desenvolvida rapidamente por meio de encontros on-line e presenciais fora do nosso espaço e/ou horário de trabalho. $O$ projeto foi fechado com um texto teórico sobre a relevância do tema, bem como uma proposta de cronograma ${ }^{6}$.

O convite feito pela Elaine para compor um trio de escrita a fim de viabilizar um Projeto Interdisciplinar que versasse de maneira comprometida sobre a temática da cultura afro-brasileira para além dos clichês do Dia da Consciência Negra encheu-me de alegria. Enquanto mulher branca não poderia ansiar de maneira tão subjetiva quanto outras professoras da escola por um projeto como esse - por motivos óbvios - mas entendo a pertinência social, política, cultural e socioemocional que um trabalho como esse possibilitaria nas dinâmicas do cotidiano escolar. Colocarme em lugar de escuta e acolhimento, propagar outras vozes, vozes silenciadas em meio a uma estrutura que ecoa exclusão e apagamento seria um esforço que desempenharia com um sorriso no rosto, mesmo ciente das pedras que poderiam rolar dessa montanha a ser escalada. Devo confessar que

\footnotetext{
${ }^{6}$ Ver Anexo 1.

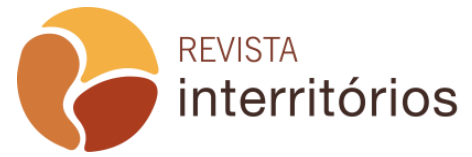

Interritórios | Revista de Educação Universidade Federal de Pernambuco, Caruaru, BRASIL | V.6 N.12 [2020] 
teoricamente sentia-me minimamente preparada, considerando que minha formação enquanto Cientista Social contemplou a temática referencial do projeto, mas autores negros com teorias relacionadas a discussão estiveram longe de serem adequadamente representados na bibliografia do curso na Pontifícia Universidade Católica de Campinas (PUCCampinas). ${ }^{7}$ Tanto é, que, considerando o tempo hábil para elaboração do Projeto, cometi de maneira consciente - e tristemente - o contrassenso de utilizar majoritariamente bibliografia branca. Tentei de maneira mais honesta, comprometida e diligente possível reparar tal incoerência para as discussões realizadas no presente trabalho. [Tamires]

Inicialmente, para embasamento teórico, trouxemos as diferentes legislações que atribuem legitimidade para a pertinência do projeto escolar no contexto sociocultural, não apenas para as especificidades da identidade brasileira, mas ainda, e sobretudo, para as especificidades da comunidade escolar. Dentre elas incluímos: a Lei 10.639/03 que propõe novas diretrizes curriculares para o estudo da história e cultura afro-brasileira e africana, alterada pela lei 11.645/08, que torna obrigatório o ensino da história e cultura afrobrasileira e africana em todas as escolas, públicas e particulares, da educação básica; o dia Nacional da Consciência Negra (20 de novembro), instituído no calendário nacional em homenagem ao dia da morte do líder quilombola negro Zumbi dos Palmares, persona representativa para o Movimento Negro ${ }^{8}$ que sintetiza a luta contínua por justiça e equidade social.

Apresentamos alguns autores que tratam das especificidades das relações de raça/etnia para a sociedade brasileira. Seja para a crítica feita à romantização do processo de miscigenação empreendido por Gilberto Freyre, em "Casa Grande e Senzala" (1933), para a problematização do que se entende como democracia racial desenvolvida sabiamente por Florestan Fernandes (1972), as singularidades do preconceito racial que se apresenta no Brasil estudadas por Oracy Nogueira (2007), ou ainda os pormenores apresentados por Daniela Finco e Fabiana de Oliveira em "A sociologia da pequena infância e a diversidade de gênero e de raça nas instituições de educação infantil” (2011)

\footnotetext{
${ }^{7}$ Somos atravessadas pelos lugares também. Campinas foi a última cidade a abolir a escravidão e a PUC-Campinas está nesse contexto de uma cidade ainda por ser descolonizada no pensamento. (CÂMARA MUNICIPAL DE CAMPINAS, 2018).

${ }^{8}$ Ressalta-se aqui, o protagonismo dos movimentos negros que se colocaram historicamente em luta e resistência à escravatura e à opressão sofrida pelos sujeitos negros, no Brasil. $\mathrm{A}$ insurgência de quilombos como maneira coletiva de organização contra a escravidão apresentou os primeiros formatos de estratégias de resistência que pautariam os movimentos atuais. A atuação do Movimento Negro produziu a mobilização necessária pela criação de jornais, instituições, programas de ação e denúncias constantes que ofereceram caminhos para o estabelecimento de direitos que possibilitassem a superação da discriminação racial. Como exemplo claro dessas conquistas, evidenciamos as normativas específicas para tais questões, implementadas na educação básica, e que ainda proporcionaram reflexos positivos para o ensino superior e a formação de professores. (SILVA, Paulo Vinicius B. da; TRIGO, Rosa Amália. E.; MARÇAL, José. Antonio, 2013).
}

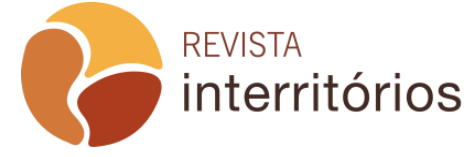


que desvelam os preconceitos envolvendo, respectivamente, gênero e raça em instituições de ensino. A sua maneira, cada autor(a) contribui para fomentar a discussão sobre as importâncias e "desimportâncias" atribuídas a figura do sujeito negro na constituição da identidade do brasileiro.

Reportagens, pesquisas e dados estatísticos desenvolvidos e/ou divulgados por fontes verificadas foram inseridos para apresentar problemáticas que envolvem encarceramento em massa, violência policial, genocídio, baixos índices de escolarização e ascensão econômica da população negra no país em comparação com a população branca. Consideramos importante a partir de dados estatísticos evidenciar a pertinência do projeto ao problematizar o real papel que o sujeito negro ocupa na estrutura social brasileira. Nesse sentido, o projeto interdisciplinar não se justificava apenas pela existência de uma legislação, por um movimento de imposição das instâncias legislativas e burocráticas para a prática pedagógica, mas principalmente pela demanda reflexiva da realidade quanto a temática étnico-racial.

Pensar em um projeto interdisciplinar, para além dos projetos e conteúdo didático já definidos no início do ano, em uma escola de grande porte é sempre um desafio. A rotina em uma escola é cansativa. O conjunto de conteúdos parece sempre maior do que os dias letivos. Unir professoras e alunos e alunas de diferentes turmas e turnos em um mesmo projeto parecia quase impossível. Mas nos comprometemos com o desafio do quase impossível e levamos para professoras e gestoras, em um HTPC (Hora de Trabalho Pedagógico Coletivo), a proposta que tínhamos à semana da Consciência Negra.

\section{Pedagogia do enfrentamento: apresentação do projeto aos pares}

Apresentar o projeto me deixou apavorada. Como as professoras iriam receber? Colocar as ideias e sugestões no papel não tinha sido difícil. A proposta, depois de pronta, parecia possível de ser implementada. Mas o tema para mim era caro. Como única professora negra do grupo e como aquela que sugeriu as colegas, parece que tinha um peso maior em minhas costas. Eu trabalhava com meus alunos a questão racial, gostava de conversar sobre os diferentes tons da cor da pele, nossos diferentes tipos de cabelo e características físicas. Aliás o meu processo de transição capilar se deu depois que me tornei professora e percebi como era significativo para minhas alunas me verem com meu cabelo crespo. Me sentia como sendo um exemplo para elas. Mas abrir isso para além da minha sala era me expor. Nunca participei de movimentos negros, conheço pouco sobre a luta antirracismo em nosso país.

Tinha em mim marcas de alguém que sentiu na pele o que é racismo e meu sentimento era que falar sobre a relevância de desenvolver um projeto sobre a Consciência Negra para um coletivo de professoras em sua maioria brancas eu seria julgada. Não teria como entrar no projeto sem tocar no assunto racismo. 
Acho que foi o que aconteceu. Na apresentação houve uma inquietação de algumas professoras, conversas paralelas, um certo descaso. Entre os comentários, algumas professoras fizeram um paralelo entre racismo e outros tipos de preconceitos como gordofobia, a criança que usa óculos etc. Tentaram colocar as questões como iguais. Eu me recordo que não consegui responder. Foi a Marina quem respondeu. Aqueles comentários me diminuíram muito, era como se o fato de ser negra não me desse autorização de falar de mim, como se o fato de defender uma pauta antirracista na escola fosse vitimismo. $\mathrm{E}$ esse foi outro ponto que surgiu na conversa. Um dos comentários é que o problema em si está na pessoa. Uma professora disse: "Por que afeta o negro uma atitude racista? Porque ele recebe e aceita". Aquele comentário me calou ainda mais...

Depois da apresentação, foi decidido pelas professoras e gestoras que o trabalho seria viável e possível de ser implementado. Em conversa posterior com a Marina ela viu mais como positiva do que negativa nossa apresentação. Eu não. Eu vi como negativa, talvez porque não dei conta de responder aquelas questões. Não me sentia preparada para aquilo. Mesmo que a proposta tinha sido aceita pela maioria das professoras, voltei para casa chorando. Os questionamentos de algumas professoras me trouxeram dúvidas se conseguiria bancar o que estava por vir. [Elaine]

A partir dessa narrativa é possível perceber as inúmeras tentativas de desvio do foco temático durante e após a apresentação que delimitam a forma com que o racismo é compreendido por uma parcela representativa da sociedade brasileira. Os discursos flertaram com o mito da democracia racial, com a equivalência entre racismo e outras opressões, e ainda com a culpabilização e tentativa de silenciamento do sujeito oprimido. O espaço tornouse, de repente, tão opressor, que a voz da única professora negra que estava na organização do projeto foi calada. Emudeceu, Kilomba (2019) em suas reflexões sobre a dificuldade da fala da mulher negra aponta como as estruturas da opressão não autorizam suas vozes e não proporcionam espaço para a articulação das mesmas, pois estamos inseridas, "dentro de um regime repressivo do colonialismo e do racismo" (KILOMBA, 2019, p. 46).

Considerar o Brasil um país assentado na democracia racial é considerar que mecanismos institucionais, sociais e culturais de segregação inexistem. As barreiras para a ascensão do negro, então, foram verdadeiramente derrubadas com o fim da escravidão e pelo avanço no processo de miscigenação? A violência policial direcionada significativamente para a população negra, o número de condenações por tráfico superior ao número de condenações de brancos com maiores quantidades de drogas ilícitas, ou ainda a exclusão sistemática da escola (ora na sala de aula, ora da própria instituição) sofrida pelos sujeitos negros tratam, então, de um "delírio coletivo"? (EXAME, 2019; FERREIRA, 2019; JUSBRASIL, 2014). O mito reside na democracia racial, não

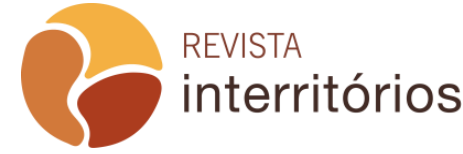

Interritórios | Revista de Educação Universidade Federal de Pernambuco, Caruaru, BRASIL | V.6 N.12 [2020] 
no estado de exceção onde a população negra foi coercitivamente alocada. É necessário, ainda, lembrar o que Sueli Carneiro expõe sobre o processo violento de miscigenação, onde:

O estupro colonial da mulher negra pelo homem branco no passado e a miscigenação daí decorrente criaram as bases para a fundação do mito da cordialidade e democracia racial brasileira A apropriação sexual da mulher branca pelo homem negro na contemporaneidade [...] o mito da ascensão social do homem negro escondendo através do subterfúgio da primazia estética e social da mulher branca o desejo de pertencimento e de aliança com um mundo restrito aos homens brancos no qual para adentrar homens negros em suposto processo de ascensão social utilizariam-se de mulheres brancas como avalistas. (CARNEIRO, 1995, p. 543).

A equiparação do racismo enquanto problemática estrutural com outros preconceitos só é possível se for totalmente descartado o modus operandi sistêmico de algo que se configura não enquanto simples ato ou conjunto de atos, mas sim como um processo caracterizado pela subalternidade e privilégios que se distribuem de maneira desigual entre diferentes grupos raciais, e que se desdobram em absolutamente todos os aspectos de existência das identidades. (ALMEIDA, 2020, p.34). Sobre essa discussão, Carneiro (2011, p. 163) afirma que para o avanço na luta contra as desigualdades raciais é necessário reconhecer

[...] sem medo, as injustiças e discriminações históricas sofridas por segmentos raciais e buscar mecanismos capazes de interromper a saga de exclusão de uns, em que se sustentam tantos privilégios ou tratamento preferencial de que gozam outros em nossa sociedade.

A culpabilização do sujeito negro como aquele que aceita a opressão de maneira casta ou que imprime ele mesmo em si e a outros sujeitos as marcas da discriminação racial é desconhecer os processos pelos quais as estruturas sociais e os papéis assumidos se estabelecem. Estatisticamente ocupando cargos de menor prestígio social e com menor remuneração, baixos índices de escolarização, com representações estigmatizadas em filmes e novelas como empregados(as), chefes de tráfico ou escravos, naturaliza-se o olhar para com esse grupo étnico-racial, inclusive no próprio sujeito negro. Retrata-se a representação do imaginário social sobre as pessoas negras, sendo assim, a ideologia que molda tais representações não se configura como reflexo da realidade concreta, mas das relações que temos com as relações concretas que estruturam tal realidade. São essas relações do campo ideológico que desenham uma estrutura onde a representação do sujeito negro é a do bandido, incapaz e escravizado. (ALMEIDA, 2020, p. 65-66; G1, 2018). 
Em nossa reunião posterior observamos que as apresentações foram comparativamente positivas em relação à anterior.

A maioria das professoras gostaram muito do projeto e viram como viável. Foi acordado que as sondagens de escrita das turmas da manhã (um $3^{\circ}$ ano, quatro $4^{\circ}$ anos e cinco $5^{\circ}$ anos) referentes ao mês de novembro seriam vinculadas a temática africana, seja pelos textos, parlendas ou pelas palavras, algo extremamente significativo considerando a relação entre 0 resultado da sondagem de escrita das turmas e o prestígio de suas respectivas professoras.

Durante toda a apresentação era quase que unanimidade 0 aceno de "sim" com a cabeça para todas as informações trazidas. No entanto, era nítido o incômodo de alguns colegas, em específico de Jéssica, com todos os relatos inseridos a partir de dados estatísticos e históricos que seguiam, uma a uma. Procurei detalhar cada informação da melhor maneira, com toda a "firmeza" e "certeza" da narrativa escolhida por mim àquela reunião, minutos antes de seu início, afinal, já fora alertada pelas minhas parceiras quanto ao tom que se seguiu na reunião da manhã. Em alguns momentos ocorreram intervenções de uma gestora em favor do que estava sendo apresentado, frente aos questionamentos de Jéssica quanto a veracidade daquilo que era exposto. Em alguns momentos o que me parecia é que Jéssica estava próxima ao que eu poderia descrever como "ponto de ebulição", tamanho o incômodo e - talvez - a dificuldade em contestar para além dos "acho que" e "penso que".

Talvez por conveniência, talvez por desencargo de consciência - ou sabe-se lá o que de fato seria - percebi certa pressão das gestoras para que todas as professoras aceitassem o projeto, pois aquelas que ficaram em dúvida, que se manifestaram resistentes ao desenvolvimento da proposta ou sem interesse em aderir a ideia foram lembradas pelas gestoras quanto a obrigatoriedade da inserção da temática da cultura afrobrasileira no currículo e conteúdo de todos os anos da educação básica, além da ausência de um projeto próprio para a escola voltado a tal temática. Assim, iniciamos nossas atividades. [Tamires]

Pelo exposto acima fica evidente as diferenças entre os pares de um mesmo meio profissional - a instituição de ensino - e a aparente preocupação com a geração de conflitos. O que consideramos, no entanto, é que para o aprimoramento da prática educativa nunca se fez tão necessário o uso dos conflitos e antagonismos sociais para fomentar pensamentos e ideias inovadoras que integrem os sujeitos interessados no processo formativo de maneira fluída e efetiva. (HOOKS, 2017, p. 154).

Ao observarmos na narrativa o incômodo em relação aos dados apresentados por parte de uma das colegas, voltamos para Grada Kilomba (2019) sobre o medo branco de assuntos como escravidão, colonialismo, 
racismo. Mantém-se segredo sobre certas verdades. É melhor negá-las e reprimi-las, mantê-las longe da consciência, "Uma vez confrontado com verdades desconfortáveis dessa história muito suja, o sujeito branco comumente argumenta 'não saber...', 'não entender...', 'não se lembrar...', 'não acreditar...' ou 'não estar convencido...'" (KILOMBA, 2019, p. 42).

Havia interesse por parte das gestoras que o projeto ocorresse, pois estava no currículo trabalhar a cultura afro-brasileira, mas havia um incomodo, quase uma não aceitação sobre os dados que levamos sobre a relevância e urgência do projeto em questão. Em nossa proposta salientamos para as professoras que o dia da Consciência Negra é marcado pela luta contra o preconceito racial no Brasil e, aquela seria uma semana importante trabalharmos a história ligada ao período da escravidão negra africana, mas também a história e cultura afro-brasileira como constituinte e formadora da sociedade, na qual os negros são considerados como sujeitos históricos, valorizando-se, portanto, o pensamento e as ideias de importantes intelectuais negros brasileiros, a cultura (música, culinária, dança) e as religiões de matrizes africanas. Como nos lembra Oliveira,

\begin{abstract}
O nosso país sempre buscou caracterizar-se pelo seu lado europeu e ocidental, ficando a porção africana relacionada à história da escravidão e suas consequências. Isso foi algo danoso para toda a população afrodescendentes, pois deixou relegado ao esquecimento, quase apagada, a ideia de povos africanos soberanos, presentes na história da civilização humana. Mesmo o Egito, apesar de sua localização geográfica no continente africano, foi 'desafricanizado' e, mais do que isso, embranquecido. (OLIVEIRA, 2009, p. 13).
\end{abstract}

Assim, a intenção com o projeto foi borrar a identidade de um currículo escolar que apresenta hegemonicamente temas e conteúdos tomados como universais, afirmando outros saberes. No caso aqui, saberes produzidos por uma população específica, a população africana que no encontro com indivíduos presentes no território brasileiro produziram o que chamamos hoje de cultura afro-brasileira. $O$ compromisso com a diversificação de conteúdos e referências de maneira intencionalizada se volta para o enfrentamento do que Silvio Almeida (2020, p. 102) chama de "regras de exclusão", isto é, as regras de pertencimento que a partir de uma dada formação social reconhecem determinadas identidades e excluem outras. Tal apagamento identitário da diáspora africana e sua relevância para a sociedade brasileira enfraquece o sentimento de pertença dos afrodescendentes no país, ao mesmo passo que estabelece valor de "desimportância" para a constituição do Brasil enquanto nação. Essa lacuna histórica abre espaço para 0 depósito de valoração negativa criada ideologicamente para manutenção das pessoas negras enquanto grupo marginalizado. (ALMEIDA, 2020). 
Intuindo o livre transitar dos saberes por todas as disciplinas do currículo, foram feitas sugestões em diferentes direcionamentos. Por exemplo: em geografia poderíamos operar com a geopolítica do continente africano, os diferentes países da África e suas diferenças culturais - idioma, práticas corporais, alimentação, fazendo sempre a ponte com a produção dessa população em terras brasileiras; nas aulas de história poderíamos apurar uma história do presente, das próprias crianças, dos seus responsáveis, dos funcionários da escola, poderíamos também dar visibilidade às comunidades quilombolas, principalmente localizadas no estado de São Paulo; em português poderíamos realizar um trabalho a partir das biografias das personalidades negras; em educação física poderíamos explorar as práticas corporais dos diferentes países africanos e com as práticas da cultura afro-brasileira como o samba, a capoeira e o maculelê; em ciências poderíamos lidar com a noção de corpo na cultura do candomblé, ao invés do corpo biologizado; e em artes poderíamos desenvolver trabalhos manuais de construção dos elementos estudados nas outras disciplinas, as máscaras ritualísticas, as pinturas faciais, construção de instrumentos musicais como tambor, ganzá que compõe também as práticas corporais e poderíamos trabalhar também com músicas, batuques e com obras de arte de Rosana Paulino que abordam questões étnicas, raciais e de gênero, na perspectiva de mulher negra ${ }^{9}$.

\title{
Pedagogia da transgressão: colorindo fronteiras
}

\begin{abstract}
Por meio de um e-mail pedimos ajuda a uma professora coordenadora da Secretaria Municipal da Educação que é envolvida com o coletivo negro da cidade. Mulher negra, que joga capoeira e tem pesquisas na área. Ela preparou um minicurso para nos receber. Envolvia teoria, mas também dança e música. Estávamos apenas eu e Marina e, naquele dia, fui muito tocada. As canções e a maneira como ela apresentou o tema e nos acolheu me emocionaram. Sou uma mulher negra, mas conheço pouco de minhas origens e naquele dia, tive a oportunidade de conhecer um pouco mais. O bom de ser professora é que aprendemos muito em nosso dia a dia. A professora cantou, dançou e tocou (a lixeira da sala, transformou-se em um tambor nas mãos dela). E nós dançamos e cantamos com ela. Foi muito emocionante. Foi meu primeiro contato com um ritmo afro-brasileiro. [Elaine]
\end{abstract}

Ao refletir sobre a narrativa acima percebe-se como foi formativa nossa iniciativa com o projeto sobre a semana da Consciência Negra. Fizemos uma busca por pessoas próximas que nos auxiliassem a levar para a escola a relevância dessa data como um espaço de reflexão sobre a cultura afro-brasileira

\footnotetext{
${ }^{9}$ Para saber mais, acessar: http://www.rosanapaulino.com.br. 
e nossas raízes. Ao agendarmos com a professora fomos com a expectativa de convidá-la para fazer alguma apresentação para os alunos e alunas, mas foi muito mais que isso. Fomos recebidas gentilmente com músicas da cultural afro, uma pasta de materiais com livros, apostilas, CD com músicas de ritmos afrobrasileiros. Mais do que nos ensinar, houve um momento sensível da constituição das professoras. A busca por apoio levou-nos ao encontro da arte. Para Vigotski, "A arte implica essa emoção dialética que reconstrói o comportamento e por isso ela sempre significa uma atividade sumamente complexa de luta interna que se conclui na catarse" (VIGOTSKI, 2010, p. 345).

Um encontro que nos propôs uma experiência estética diferenciada, principalmente ao pensar que uma de nós, professora negra, nunca tinha acessado o som do maculelê, a música e a dança circular afro-brasileira. Podemos pensar essa experiência a partir do conceito de catarse que, na teoria histórico-cultural está relacionada a uma transmutação de sentimentos - uma alteração profunda, dramática e contraditória dos nossos sentidos, anseios e condutas. (MOREIRA, SILVA, 2020, p.50).

Ali, a experiência estética vivida foi para além de uma vivência social, tocou a cada uma individualmente, mas com efeito social. A maneira como uma professora negra foi afetada no encontro com sua cultura, afetou posteriormente sua relação com o projeto e com os alunos e alunas. Pode-se dizer que foi um processo formativo mobilizador não apenas do cognitivo das professoras, mas também de seus sentidos e imaginação.

\begin{abstract}
Antes de iniciar o relato gostaria de pontuar que o que escreverei abaixo é menos uma narrativa de relato de experiência pedagógica e mais uma narrativa da experiência de constituirse professora que esse projeto possibilitou. Assim penso que seja importante situar que sou a professora de Educação Física, aquela que trabalha na quadra da escola e que de acordo com falas reproduzidas no senso comum é responsável, principalmente, pelo ensino de uma das manifestações da cultura corporal mais hegemônicas na sociedade moderna: o esporte. Além disso, sou branca e nascida em uma camada bastante favorecida da sociedade, na qual pouco tive contato com culturas que não fossem de matriz europeia. (Marina)
\end{abstract}

Apesar da professora Marina ter passado por um processo (na formação inicial e na prática cotidiana da escola) de assunção por uma forma de ser docente que rompesse com práticas de ensino hegemônicas na educação física, foi a partir do projeto que se deu a marca inicial de sua compreensão sobre a produção de uma docência militante/combativa devido a dois fatores: o trabalho coletivo e o trabalho com uma cultura que é marginalizada pelo conhecimento escolar. 
Mesmo que a legislação garanta a presença das culturas afro-brasileiras no currículo escolar é sabido que as mesmas, muitas vezes são traduzidas pela prática pedagógica com um certo distanciamento, o que atribui a essa cultura um lugar de outro da escola. Além de serem trabalhadas em momentos demasiadamente específicos do ano, elas são marcadas pela perspectiva do estranho e seus praticantes pela perspectiva do estrangeiro. Reforçando ainda mais a hierarquia entre os conhecimentos presentes no currículo, como é possível observamos na continuação da narrativa da professora Marina

Uma das ações que mais me marcou foi a demonstração e a aula de Maculelê ministrada por uma professora e batuqueira da cidade. E para que tudo acontecesse ela solicitou alguns materiais: pincéis, tintas de pintura facial, cabos de vassoura, caixa de som e um cartaz bem grande escrito Maculelê preso no espaço onde aconteceria a prática.

Esse cartaz gerou muita curiosidade nos alunos que remeteram o nome Maculelê a macumba, e conforme ela ia descarregando os materiais que utilizaria eles foram ficando ainda mais impacientes. O rosto pintado e o atabaque pareciam ser algo muito diferente. Percebia no olhar dos alunos algumas sensações ${ }^{10}$, percebia alegria no rosto de uns, curiosidade no de outros, também presenciei momentos nos quais eles pareciam estar com vergonha de realizar algumas coisas e constrangidos por nos verem fazer outras que eles julgavam inadequadas como dançar, deixar com que eles pintassem nossos rostos e cantar, comportamentos não esperados da figura da professora. Em alguns momentos eles manifestaram alguns sentimentos com gargalhadas, em outros se empenharam muito em realizar o que era pedido que fizessem e, ainda em outro, se recusaram a fazer certas coisas. Percebia-se nesse movimento a apropriação de um saber que era estranho, mas não era. Era estranho por vir de um espaço que esse saber parecia não pertencer, mas não era pôr de certa forma fazer parte da vida de algumas crianças naquele contexto.

A professora contextualizou a história do Maculelê por meio de duas canções as quais algumas turmas me fizeram repetir nas aulas de Educação Física inúmeras vezes. Eram elas:

Vim num navio de Aruanda, Aruanda aê.

Vim num navio de Aruanda, Aruanda aa.

Porque me trouxeram de Aruanda?

Pra quê me trouxeram de Aruanda?

Deixa eu voltar pra Aruanda, Aruanda aê.

Um certo dia na cabana um guerreiro

Foi atacado por uma tribo pra valer ${ }^{10}$ Gostaria de pontuar que são significações minhas aos sentimentos dos mesmos e não
necessariamente o que de fato passava na cabeça deles. 
Pegou dois paus,

Saiu de salto mortal

E gritou pula menino

Que eu sou Maculelê.

\begin{abstract}
Alguns alunos também conseguiram perceber semelhanças entre o Maculêle e práticas com as quais eles possuíam mais familiaridade. Levantaram que a base do Maculêle é parecida com a ginga na capoeira, perceberam a roda como elemento comum entre as práticas Maculelê, Capoeira e Samba. Práticas estas que também poderiam servir posteriormente como objeto de estudo na escola. Práticas estas que por vezes achamos não contemplar os conhecimentos universais de aquisição obrigatória. (Marina)
\end{abstract}

Quando olhamos para a narrativa da Marina somos movidos a pensar no processo de constituição docente que ocorre no cotidiano escolar por meio da parceria e do encontro com outros sujeitos. A professora Marina se permitiu um movimento de saída do espaço de conforto, do ensino de manifestações culturais hegemônicas, como o esporte, para encontrar-se com saberes sociais, culturais e científicos que the eram desconhecidos. Uma cultura "marginalizada pelo conhecimento escolar", mas que, ao longo de sua narrativa, percebemos que 0 Maculelê era em simultâneo estranho e familiar aos alunos e alunas.

Naquele espaço/tempo deu-se a construção de uma docência que considera princípios ético-políticos, como a justiça e a afirmação de uma vida ética no desenvolver de uma prática pedagógica, que combata a hierarquização de saberes e valores e enalteça a escola enquanto um espaço de partilhas e de possibilidades. Um espaço de criação e suspensão, no qual possamos olhar para nossos objetos e compreendê-los enquanto elementos da cultura que nos modificam, e também, como elementos modificáveis, que não representam verdades absolutas sobre a realidade.

\title{
Pedagogia do diálogo: sublinhe nossas vozes, não as cicatrizes
}

Me recordo que foi um mês de estudo intenso e de muitas parcerias, buscávamos pessoas que tinham autoridade para tratar dos assuntos que atravessavam as falas cotidianas dos alunos sobre o preconceito, o cabelo, a visibilidade da negritude. Tenho a impressão de que a todo momento, durante aquele período, chacoalhamos a representação da docência autoridade. Quem mobilizava os debates eram as questões trazidas pelos alunos, quem aprofundava os temas eram convidadas pretas que aproximaram a escola da vida fora dela, como se as paredes da mesma tivessem sido removidas e como se o saber da rua a tivesse tomado de pronto. (Marina) 
Um dos objetivos que tínhamos com o projeto era ouvir os alunos e alunas, era proporcionar espaços para que eles/elas falassem de si e de suas impressões sobre o tema. No momento da construção do projeto não conhecíamos a obra de Hampaté Bâ (2003), sobre a tradição oral como marca fundante da raiz africana. Mas, ainda assim, em nossas conversas e na organização do material ansiávamos em dar voz aos nossos alunos e alunas.

Uma das propostas mais audaciosas e desejadas, falando por mim, era a roda de conversa. Eu mais que depressa inseri a roda de conversa no planejamento semanal da turma. Os $4^{\circ}$ anos desenvolviam algumas atividades "permanentes", isto é, atividades que aconteciam durante todo 0 ano, mas não possuíam um produto. Uma delas era a roda de jornal. A temática da roda escolhida para a semana foi "PRECONCEITO RACIAL" e a notícia-referência era sobre os lamentos do jogador Willian por vivenciar o racismo contra brasileiros na Ucrânia, e sua postura em solicitar posicionamento das entidades esportivas, publicada pelo jornal $O$ Estado de São Paulo. (ESTADÃO, 2019).

Iniciei a organização da sala afastando as carteiras e solicitando que cada um pegasse sua cadeira e as organizasse em roda, o que não foi tão difícil, pois mesmo que inicialmente essa movimentação cause certa "confusão", já vinha trabalhando diferentes organizações da sala com eles, além de estabelecer a dinâmica de rodas de conversa em outros momentos. A disposição da sala de maneira diferenciada era sempre muito bem recebida, eles claramente apreciavam. Expliquei que faríamos a roda de jornal e que precisaria da ajuda deles. "Como, prô?", com um sorriso de curiosidade, alegria e certa apreensão. "Preciso que vocês conversem entre vocês, e que conversem comigo". Muitos riram, parecia engraçado uma professora com uma necessidade dessas. Tão incomum, não é mesmo? Como de costume expliquei que deveríamos falar com respeito, considerando os sentimentos do outro, sem atropelos, levantando as mãos para que todos tivessem oportunidade de falar. Foi a aula em que menos falei, coloquei-me a disposição como mediadora e fui surpreendida. As crianças guiaram a discussão, com provocações, réplicas e tréplicas entre eles, de maneira construtiva, questionadora. Ouvi experiências, dores, palavras de resistência, tudo da maneira mais verdadeira e necessária que eu, mulher branca, poderia vivenciar. "Brancos não gostam de nada dos negros, acham o cabelo feio", "Brancos não aceitam que negros sejam melhores". Algumas das frases ditas pelos alunos auto identificados como negros da turma.

$O$ aluno Alexandre foi apontado como alguém que ridicularizava a colega de outra turma por seu cabelo crespo e volumoso. Então, o aluno Henrique, que se auto declarava como negro, disse: "Você é um racista, Alexandre! Não tem respeito pelas pessoas". Aquele aluno, até então, sempre fora mais introspectivo, sem posturas muito assertivas. Extremamente brincalhão com os amigos e muito doce. Naquele dia o vi rasgar. Aquelas palavras saíram como quem emerge a superfície de um 
rio após tempos segurando o ar embaixo d'água. Na mediação procurei legitimar aquela dor e revolta, disse que estava tudo bem e que era importante Henrique falar sobre o que sentia e pensava, e que Alexandre precisava pensar sobre as razões que o levavam a atacar a colega usando aqueles argumentos. "Por que o cabelo crespo é motivo de zombaria?". Alexandre acenava com sinal de confusão e Henrique que respirava profundamente como quem perdera o fôlego era acolhido pelos amigos. "Calma, Henrique. Não fica assim, se acalma, cara".

A aluna Nicolly que tinha alisado o cabelo (antes crespo) há poucas semanas afirmou que não tinha alisado por pressão, que não era negra nem branca, mas que alisou o cabelo porque quis, não por racismo. Nesse momento, a aluna Giorgia, que se auto declarava negra, prontamente se manifestou: "Claro que negros alisam o cabelo, as pessoas só falam que é feio e que preferem cabelo liso. Branco só fala mal de cabelo de gente negra". Trêmula, com os olhos bem abertos e os punhos cerrados, Giorgia olhava fixamente para Nicolly, proferindo aquelas palavras em tom de revolta, mágoa e indignação. Seu rosto, com bochechas sempre avermelhadas naturalmente ficaram ainda mais rubras, as veias no delicado pescoço pulsavam e eu sentia como se todo o esforço daquele ser estivesse empreendido em soltar aquelas palavras, pois elas saiam como se estivessem se desentalando de um lugar muito apertado e profundo. Meu primeiro pensamento foi abraçá-la, mas escolhi deixá-la libertarse do que a sufocava. Tão difícil e custoso. Mas necessário. [Tamires]

Através de experiências como essas deparamo-nos com o que Hooks (2017) afirma possibilitar a transgressão das estruturas hierárquicas e de opressão na educação, ao proporcionar na sala de aula espaços seguros abertos ao conflito, as discordâncias. Como a autora bem pontua, não é tarefa fácil, em alguns momentos pode ser - inclusive - desesperador abrir mão enquanto professora em posição hierárquica privilegiada ou enquanto sujeito branco dotado de privilégios mantidos pela exclusão e marginalização dos sujeitos negros.

Raça, gênero e/ou classe social são categorias de debate pertinentes a realidade das salas de aula etnicamente e culturalmente diversificadas, e são questões pertinentes a reconfiguração do espaço escolar enquanto esfera de democratização das relações. A importância de questionar a constituição do conhecimento como algo elaborado intencionalmente demanda tanto dos educandos, quanto dos profissionais da educação, que se viva o presente, e tal engajamento no agora possibilita a educação como prática da liberdade pela consciência em tempo real daquilo que se vive. (HOOKS, 2019).

\section{CONSIDERAÇÕES FINAIS}


Quando pensamos no projeto a ser implementado na escola e, ao longo de todo o trabalhado desenvolvido, não tínhamos planos em sistematizar os relatos por meio de narrativas. Assim, para compor esse ensaio mobilizamos lembranças que moveram e ainda movem a construção de uma docência. $O$ processo que teve início com uma professora negra inquieta, que desejava ver a cultura afro-brasileira contemplada no currículo escolar, alcançou um coletivo, mobilizou uma comunidade escolar. Foram trocas de relatos e experiências entre professoras, alunos, alunas e convidados.

A figura de professora, aqui, se inscreve no movimento dialógico de quem sujeita e se sujeita, corpo que transforma outros corpos e é colateralmente transformado. A partir do entendimento de realidades que não estão dadas, mas que servem a propósitos determinados, subentende-se a necessidade de refletir sobre a prática pedagógica e sua germinação política no sentido de viabilizar a formação humana para além da transmissão de conhecimentos técnicos e científicos. Mediar a descoberta para os caminhos da desconfiança do mundo, do real, das invenções, dos fenômenos e das regras por nós mesmas tão difundidas. Desconfiar de verdades crônicas.

Entendemos que a escola precisa avançar na luta contra as desigualdades raciais, comprometendo-se com a diversificação do currículo, trazendo conteúdos e referências de maneira intencional, não aceitando mais a exclusão da cultura africana e sua relevância para a sociedade brasileira. É necessário erguer as vozes e trazer para a discussão assuntos como racismo, colonialismo, preconceito racial. Vislumbramos e acreditamos que projetos como esse que inspiram o sublinhar de diferentes vozes, nunca ou raramente escutadas pela instituição escolar, potencializam o caráter transformador da educação na qual acreditamos. Conhecer quem fala é saber a quem se ensina e essa caberia como prerrogativa básica para a prática educativa, seja ela formal ou não.

Foi possível observar que, mesmo estando na lei que o currículo escolar deve contemplar a cultura afro-brasileira, todo o processo de implementação do projeto foi desafiador. A escola, como reflexo da sociedade atual é atravessada por discursos do mito da democracia racial, da equivalência entre racismo e outras opressões, da culpabilização e tentativa de silenciamento do sujeito oprimido, como percebemos por meio das narrativas. É nesse ponto onde o espanto se faz necessário, o espanto para com algo descabido pensando a formação social, cultural e política da sociedade brasileira. A partir desse estranhamento deixamo-nos tomar pela curiosidade que mobiliza nossos olhares e mãos à prática transgressora em sala de aula. Como ressignificar essas relações?

Cada aluno e aluna é um ser completo, em sua totalidade complexa e atravessado por histórias, sonhos, anseios, pela dor. Seria negligência, e em certo grau ingenuidade, presumir que o desenvolvimento de projetos, como esse

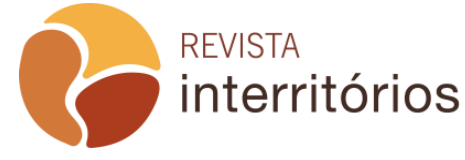


aqui apresentado, aconteceriam sem o entrelaçamento de histórias e memórias que se veem representadas por uma prática organizada, teoricamente embasada e modulada em diretrizes de "experiências ideais" a serem oportunizadas. O que pudemos vivenciar em caráter revolucionário de nosso pequeno infinito circunscrito no chão daquela escola periférica talvez represente o vivenciar de um pertencimento, por nossos alunos e alunas negros e não brancos, cotidianamente preterido pelo tradicionalismo conservador cimentados nas paredes das instituições de ensino.

Pequenos brilhantes puderam reluzir o céu da escola em escalas significativas. Entramos pelas rachaduras das paredes para preencher e fortificar as estruturas de pertença de nossos alunos e alunas negros, procuramos perambular os corredores escolares na contramão do senso comum perpassado por conhecimentos filosóficos, científicos, religiosos, culturais, políticos e sociais e que, em menor ou maior grau, a depender do contexto, deslegitima e/ou inviabiliza a pluralidade de "ser no mundo". Corremos contra a hegemonia branca e euro centrada pela prática do acolhimento, do abraço, da música, do escutar, do sentir, do sorrir, do lutar.

\section{REFERÊNCIAS}

ALMEIDA, Silvio Luiz de. Racismo Estrutural. São Paulo: Sueli Carneiro; Editora Jandaíra, 2020.

BA HAMPATÊ, Amadoul. Amkoullel. O menino fula. São Paulo: Palas ATHENA, 2003.

CÂMARA MUNICIPAL DE CAMPINAS. Verdades históricas: câmara assina convênio para que Comissão da Verdade Sobre a Escravidão Negra tenha acesso ao acervo documental do legislativo, um dos maiores sobre o século XIX. 2018. Disponível em:

<https://www.campinas.sp.leg.br/comunicacao/noticias/2018/maio/verdades-historicascamara-assina-convenio-para-que-comissao-da-verdade-sobre-a-escravidao-negratenha-acesso-ao-acervo-documental-do-legislativo-um-dos-maiores-sobre-o-seculoxix>. Acesso em 16 de setembro de 2020.

CARNEIRO, Sueli. Gênero Raça e Ascensão Social. Revista Estudos Feministas, Florianópolis, v. 3, n. 2, p. 544, jan. 1995. ISSN 1806-9584. Disponível em: <https://periodicos.ufsc.br/index.php/ref/article/view/16472/15042>. Acesso em: 21 ago. 2020.

CARNEIRO, Sueli. Racismo, sexismo e desigualdade no Brasil. São Paulo: Selo Negro, 2011.

DELORY-MOMBERGER, Christine. Biografia e Educação: figuras do indivíduoprojeto. Tradução: Maria da Conceição Passegi, João Gomes da Silva Neto e Luis Passegi. Natal, RN: EDUFRN; São Paulo: Paulus, 2008. 
ESTADÃO. O material jornalístico produzido pelo Estadão é protegido por lei. As regras têm como objetivo proteger o investimento feito pelo Estadão na qualidade constante de seu jornalismo. 2019. Disponível em

$<$ https://esportes.estadao.com.br/noticias/futebol,willian-lamenta-racismo-contrabrasileiros-na-ucrania-e-cobra-entidades,70003085100>. Acesso em 16 de setembro de 2020.

EXAME. Negros são os mais condenados por tráfico e com menos drogas apreendidas. 2019. Disponível em: <https://exame.com/brasil/negros-sao-maiscondenados-por-trafico-e-com-menos-drogas-em-sao-paulo/>. Acesso em 21 de agosto de 2020.

FERREIRA, Luciana Haddad; ARAGÃO, Ana Maria Falcão; PREZOTTO, Marissol. Sobre águas e meninos: formação de professores numa perspectiva histórico-cultural. Laplage em Revista (Sorocaba), vol.1, n.3, 2015a, p.20-33.

G1. Brancos são maioria em empregos de elite e negros ocupam vagas sem qualificação. 2018. Disponível em: <https://g1.globo.com/economia/noticia/brancossao-maioria-em-empregos-de-elite-e-negros-ocupam-vagas-sem-qualificacao.ghtml>. Acesso em 21 de agosto de 2020.

HOOKS, bell. Educação democrática. In: CÁSSIO, Fernando (org.). Educação contra a barbárie: por escolas democráticas e pela liberdade de ensinar.1. ed. São Paulo: Boitempo, 2019.

HOOKS, bell. Ensinando a transgredir: a educação como prática da liberdade. Tradução: Marcelo Brandão Cipolla. 2. Ed. São Paulo: Editora WMF Martins Fontes, 2017.

JUSBRASIL. Estudo sobre violência policial revela racismo institucional na PM de SP. Disponível em: <https://lunatenorio.jusbrasil.com.br/artigos/114873464/estudosobre-violencia-policial-revela-racismo-institucional-na-pm-de-sp>. Acesso em 21 de agosto de 2020.

KILOMBA, Grada. Memórias da Plantação: Episódios de racismo cotidiano. Rio de Janeiro: Ed. Cobogó, 2019.

MARQUESIN, Denise F. B., NACARATO, Adair, M. Narrativas de futuras professoras: paisagens desenhadas sobre os modos de ensinar matemática. In: NARCARATO, Adair (org.) Pesquisa (com) Narrativas: A produção de sentidos para experiências discentes e docentes. São Paulo: Editora Livraria da Física, 2018.

MOREIRA, Andressa; SILVA, Daniele N. H. Experiência Estética, arte, imaginação e criação na psicologia de Lev Vigotski. In: Educação Estética: a arte como atividade educativa. São Carlos: Pedro \& João Editores, 2020.

PRADO, Guilherme do Val T.et al. Formação de professores em narrativas singulares. In:IMBERNÓN, Francisco, NETO, Alexandre S. \& FORTUNATO, Ivan (org.). São Paulo: Edições Hipótese, 2019.

RUBTSOV, Vitaly. A atividade de aprendizado e os problemas referentes à formação do pensamento teórico dos escolares. Em Garnier, Catherine, Bednarz, Nadine, \& Ulanovskaya, Irina. (1996). Após Vygotsky e Piaget: Perspectivas Social e Construtivista. Escolas russa e ocidental (pp.129-137). Porto Alegre: Artes Médicas.

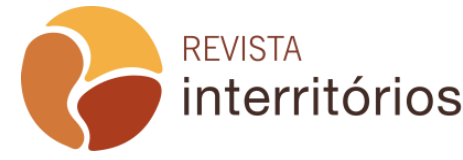


SILVA, Paulo Vinicius B. da; TRIGO, Rosa Amália. E.; MARÇAL, José Antonio.

Movimentos negros e direitos humanos. Rev. Diálogo Educ., Curitiba, v. 13, n. 39, p. 559-581, maio/ago. 2013. Disponível em:

<https://periodicos.pucpr.br/index.php/dialogoeducacional/article/view/8276/0>. Acesso em 16 de setembro de 2020.

VIGOTSKI, L. S. Psicologia Pedagógica. 3ª ed. São Paulo: Martins Fontes, 2010.

\section{ANEXO}

Anexo 1. Tabela com proposta de cronograma para desenvolvimento do projeto interdisciplinar no mês da Consciência Negra.

\begin{tabular}{|c|c|}
\hline \multicolumn{2}{|r|}{ CRONOGRAMA } \\
\hline DATA & PROPOSTA DE ATIVIDADES A SEREM APLICADAS \\
\hline 04/nov & $\begin{array}{l}\text { Apresentação em HTPC da Proposta de Trabalho Interdisciplinar sobre a } \\
\text { Semana da Consciência Negra. [04 a } 08 \text { professoras estudarem a Proposta } \\
\text { de Trabalho Interdisciplinar e verificar a possibilidade de encaixar no } \\
\text { planejamento]. }\end{array}$ \\
\hline $07 /$ nov e $08 /$ nov & $\begin{array}{l}\text { Censo identitário com os alunos (como você se considera?) - responsável } \\
\text { manhã - Tamires e Marina, responsável tarde - Elaine e Marina } \\
\text { Objetivo do censo: Identificar a composição racial da escola a partir da } \\
\text { percepção da própria criança. }\end{array}$ \\
\hline $11 /$ nov & $\begin{array}{l}\text { Roda da Conversa sobre Preconceito. Período da manhã e tarde com } \\
\text { duração de } 50 \text { minutos cada turma. (Responsável período da manhã: Elaine } \\
\text { e Marina; responsável período da tarde Tamires - com participação e apoio } \\
\text { das professoras da sala). }\end{array}$ \\
\hline $11 /$ nov a $14 /$ nov & $\begin{array}{l}\text { Trazer para as aulas textos, relatos, narrativas, poesias, músicas sobre o } \\
\text { tema. Aproveitar aulas de Geografia e História e o período da leitura diária. } \\
\text { (incluímos no projeto inicial um anexo como sugestões de materiais e textos } \\
\text { que poderiam ser trabalhado pelas professoras). }\end{array}$ \\
\hline $13 /$ nov e $14 /$ nov & $\begin{array}{l}\text { Os painéis do pátio da escola serão confeccionados pelas professoras } \\
\text { Marina, Elaine e Tamires sobre personas relevantes para a cultura afro- } \\
\text { brasileira. Dois dos painéis serão destinados às personalidades negras da } \\
\text { escola. As professoras da sala poderão se organizar para levar as turmas } \\
\text { para visitarem a exposição entre } 18 / 11 \text { a } 22 / 11\end{array}$ \\
\hline \multicolumn{2}{|r|}{ SEMANA DA CONSCIÉNCIA NEGRA } \\
\hline 18/nov & Data limite para a organização dos murais com as atividades dos alunos \\
\hline 18/nov e 19/nov & Contação de História após os intervalos do recreio \\
\hline $21 /$ nov & $\begin{array}{l}\text { Oficina Bonecas Abayomi. Material necessário: Tecido preto e colorido - } \\
\text { retalhos. Sugestão: Oficina para aula de artes a serem ministradas pelas } \\
\text { professoras na sala que tiverem interesse. (Ponte com a cosmologia) } \\
\text { NOTA: Para aquelas que acham difícil ministrar a oficina, sugerimos filmes } \\
\text { ou documentários. (VER ANEXOS) }\end{array}$ \\
\hline 21/nov & $\begin{array}{l}\text { Vivências sobre Danças de Origem Africana (Maculelê) - Priscila período da } \\
\text { manhã (específicos para os alunos do } 5^{\circ} \text { ano) }\end{array}$ \\
\hline $22 / n o v$ & Encerramento do Projeto com sorteio de brindes e a contação de história \\
\hline
\end{tabular}

